\title{
Linearization and discretization risks in knowledge management
}

\author{
Constantin BRATIANU \\ Bucharest University of Economic Studies, Bucharest, Romania \\ constantin.bratianu@gmail.com
}

PICBE | 448

\begin{abstract}
The purpose of this paper is to analyze the limitations induced in Knowledge Management by the processes of linearization and discretization, which happen frequently in decision-making. Linearization is a result of applying linear thinking models in decision-making, regardless of the complexity of knowledge management phenomena. Knowledge and all the other intangible resources are nonlinear entities and they should be evaluated with nonlinear metrics. However, in many situations managers use simple solutions based on linear thinking models and get large errors in their decisionmaking, with significant negative consequences in management. Also, linear thinking model is dominant in legislation, which may lead to significant errors in managerial decision-making. Discretization is a process in which an entity with a continuous representation, like a knowledge field, is transformed into a piecewise entity to be handled more easily. Also, social media uses discretized systems for different evaluations which should be interpreted accordingly. For instance, counting the number of "like" on Facebook for a certain message or image may lead to the conclusion that friendship is proportional with the number of "friends", which might not be in concordance with reality. Knowledge management is a complex activity dealing with knowledge, which means nonlinear entities. Using linear thinking models and discretization methods in evaluations and decision-making may lead to significant errors and negative consequences.
\end{abstract}

Keywords: knowledge, knowledge management, intellectual capital, intangible resources, linearization, discretization

\section{Introduction}

The emergence of knowledge management (Jashapara, 2011; Nonaka \& Takeuchi, 1995) is related to the development of knowledge economy (Edvinsson, 2002; Hadad, 2017; Powell \& Snellman, 2004), which is based on the dominance of intangible resources (Andriessen, 2004; Stewart, 1997; Sveiby, 1997; Viedma, 2003). Knowledge management is not replacing the classical management but it deals with intangible resources, especially in the knowledge-intensive organizations. Knowledge is considered today by many researchers a strategic resource (Barney \& Clark, 2007; Grant, 1996, 1997) and a key component of core competences and dynamic capabilities (Teece, 2009) which lead to competitive advantage.

Knowledge is an abstract concept we understand through metaphorical thinking (Andriessen, 2006). It does not have any physical object as a reference. Being an abstract concept it has no physical dimensions or features, which means that it is a nonlinear entity representing only a semantic field. However, many metaphors used to explain and define knowledge use as known elements objects, stocks, flows, or stocks-and-flows (Andriessen, 2006; Bratianu, 2009a). They induce in the metaphor's target domain the idea of linearization and discretization, which leads to misinterpretations in evaluating knowledge and intellectual capital (IC) (Bratianu, 2018). Linearization is a process of applying linear thinking models to solve complex problems (Bratianu \& Vasilache, 2010), while 
discretization is a process of discretizing continuum entities in order to evaluate them (Bratianu \& Atluri, 1983).

The purpose of this paper is to analyze the risks induced by these phenomena of linearization and discretization when use them in knowledge management and intellectual capital, especially when we create metrics for evaluating intangibles. The structure of the paper is as follows: after this short introduction we make a critical literature overview, then we present the research design, results and discussions, and finally some conclusions.

\section{Literature review}

We understand the world we are living in by using thinking models or mental models, which are cognitive approximations of the complexity and infinity of this world. According to Senge (1999, p. 8), "Mental models are deeply ingrained assumptions, generalizations, or even pictures or images that influence how we understand the world and how we take action". They are developed through education and personal efforts to get a better understanding of the reality and to help us in performing the thinking process (Baron, 2000; Gharajedaghi, 2006; Ohmae, 1982). Thinking models differentiate from thinking styles, which are specific ways of thinking and are related more to personality than to the thinking process (Kolb \& Kolb, 2005; Sternberg, 1997). Actually, we 'see' the real world through these models, like through some glasses. We may even consider these thinking models as being some cognitive lenses. They have for different people different levels of complexity, knowledge entropy, efficiency and creativity, and they determine the outcomes of the decision-making processes (Keeny, 1992; Martin, 2007).

Cognitive scientists consider that we are using two modes of thinking, each of them being supported by a specific thinking system, called generically System 1 and System 2 . According to Kahneman (2011, pp. 20-21), "System 1 operates automatically and quickly, with little or no effort and no sense of voluntary control. System 2 allocates attention to the effortful mental activities that demand it, including complex computations". In other words, System 1 is based on the information received through sensory systems, which is emotional knowledge (Bratianu, 2014; Bratianu \& Orzea, 2013; Damasio, 1999, 2012; Gladwell, 2005). System 2 is based on rational knowledge and rational thinking. Vance et al. (2007), and Groves et al. (2008) associate linear thinking to the operational way of System 2, based on rational knowledge. In their perspective, linear thinking is defined as a "preference for attending to external data and facts, and processing this information through conscious logic and rational thinking to form knowledge, understanding, or a decision for guiding subsequent action" (Vance et al., 2007, p. 170). This view is in concordance with the Western epistemology (Audi, 2011) which considers knowledge to be the result of reflection and rational thinking. By contrast, nonlinear thinking is associated with System 1 and emotional knowledge and intelligence.

We adopt a different view, based on the definition and properties of mathematical linear spaces (Bratianu, 2009b). Within such linear spaces we define the known algebraic operations of summation or addition and multiplication. Addition is commutative and associative, and it allows us to introduce the identity element and the inverse element. For instance, if $\mathrm{a}$ and $\mathrm{b}$ are scalars belonging to a linear space $\mathrm{S}$, then we can write the following equations: 
$\mathrm{a}+\mathrm{b}=\mathrm{c}$, where $\mathrm{c}$ belongs also to $\mathrm{S}$ (i.e. the addition rule)

$\mathrm{a} \times \mathrm{b}=\mathrm{d}$, where $\mathrm{d}$ belongs also to $\mathrm{S}$ (i.e. the multiplication rule)

$\mathrm{a}+\mathrm{b}=\mathrm{b}+\mathrm{a}$ (i.e. addition is commutative)

$(\mathrm{a}+\mathrm{b})+\mathrm{c}=\mathrm{a}+(\mathrm{b}+\mathrm{c})$ (i.e. addition is associative)

$a+0=0+a$ (i.e. the identity element)

$a+(-a)=0$ (i.e. the inverse element)

PICBE $\mid 450$

If anybody will try to apply these equations to intangible resources will find immediately that they do not work. For instance, let us consider two different words belonging to natural language taken as a semantic space: computer and milk. Then the addition rule yields:

$$
\text { computer }+ \text { milk }=\text { compuermilk (?) }
$$

The result doesn't mean anything, so it does not belong to the semantic space. The rule of addition does not apply. Let us consider now the word white. Then we try to aply the multiplication rule:

$$
5 \mathrm{x} \text { white }=5 \text { white (?) }
$$

Again, the result does not belong to semantic space. The conclusion we arrive at is that the semantic space is not a linear space. It is a nonlinear space where linear rules do not apply. Many researchers are not aware of this problem and try to evaluate semantic entities like intellectual capital by using linear rules, which means actually a linearization process (Bratianu \& Bejinaru, 2017; Riceri, 2008; Roos et al., 2005). Dumay (2009, p. 205) remarks very well the linearization process in intellectual capital reporting, as an extension of the accounting system which operates with a linear logic: "these contemporary IC measurement frameworks are reifying IC in the same manner in which tangible assets are portrayed within accounting, which is akin to attempting to make the intangible tangible. This is what the author defines as an 'accountingisation' of IC".

Linearization is accompanied by discretization when researchers want to measure intangibles. A suggestive example can be the Law enacted in the higher education system in Austria, which requires state universities to produce by the end of each year a Report concerning their intellectual capital, starting 2006 (Habersam, 2013, 2018). The idea is interesting but its application is based on the linearization and discretization of the knowledge fields and organizational intellectual capital which leads to wrong results. For instance, among many items defined to measure the value of the intellectual capital we find: the number of professors, the number of researchers, the number of computers, the number of research grants, the financial value of these grants, and the value of the total floor area used for laboratories, in squared meters. The immediate question we may ask is how it is possible to consider that measuring that area we measure the intellectual capital of the university? It is a non-sense. Also, the evaluation of the intellectual capital should be related to the governance of the university (Bratianu \& Pinzaru, 2015; Dima et al., 2015).

After many debates, the initial set of items used for measuring the intellectual capital has been revised and reduced significantly. However, the basic principle of linearization and 
discretization remained in the reporting framework. Both Dumay (2009) and Edvinsson (2013) suggested to re-consider the whole approach of intellectual capital reporting based on linear thinking and to design new models based on complexity and nonlinearity.

\section{Methodology}

The research design is based on a complex approach from the perspective of qualitative research (Bryman \& Bell, 20017; Maxwell, 2013). We performed a critical analysis of the literature and used metaphorical thinking (Andriessen, 2006; Lakoff \& Johnson, 1999) for interpreting the semantic fields of the abstract concepts of knowledge and intellectual capital. In our perspective, metaphors are much more than writing styles; they reflect human thinking and the dynamics between consciousness and the cognitive unconscious.

The structure of any metaphor is composed of a source domain, a target domain, and a mapping function. In the source domain we put a well-known concept with its semantic attributes. In the target domain we put the less-known concept, which in our situation is knowledge. The mapping function transfers from the source domain toward the target domain some of the most significant attributes of the well-defined entity, attributes which can be associated with knowledge. Thus, the meaning of the knowledge concepts is obtained mainly from such a metaphor. Andriessen \& Boom (2007, p. 3) emphasize clearly that "Knowledge is not a concept that has a clearly delineated structure. Whatever structure it has it gets through metaphor. Different people from different culture use different metaphors to conceptualize knowledge. They may be using the same word; however, this word can refer to totally different understandings of the concept of knowledge".

Finally, we used the theory of linear spaces, and systems thinking (Gharajedaghi, 2006; Senge, (1999). Based on these theories we could realize the risks of induced linearization and discretization in knowledge management and intellectual capital which are complex and nonlinear fields of thinking and action.

\section{Results and discussions}

Linear thinking is based on the theory of linear spaces and states simply that outcomes of any transformational process should be proportional with the inputs in that process. It is a generic approximation of any complex entity or process by using linear equations and linear spaces properties. Due to its simplicity and intuitiveness, linear thinking became a dominant thinking pattern in many fields of sciences, engineering, economics and management (Ohmae, 1982; Handy, 2002; Senge, 1999). Within the linear thinking framework "We perceive the world as a series of cause-and-effect relationships in which an effect has a single cause that occurred shortly prior to the effect surfacing. This perception, in turn, prompts us to treat problems as isolated events and to solve them using a discrete, linear process of problem recognition, identification of alternatives, selection and implementation of solutions that lead to problem resolution" (Atwater et al., 2008, p. 12).

Unlike space, time is not linear. Psychological and biological time reflects our emotions and feelings, and each of us developed a specific metric to measure it. However, the time we measure using a clock is a social invention which produced a linearization and standardization of time. Thus, the official time is linear. Also, our natural language is linear, since we express our ideas by using one word after another one. Going down the basic 
constructs, words are composed of letters written one after another. More generally, in linear processes activities are produced in sequences, one after another. Classical management is based on linear thinking and many production activities are organized in such sequences. For instance, an assembly line in a plant of producing cars is a typical illustration of a linear management and linear production. Workers along such an assembly line contribute one after another to the assembling process. The construction of the first assembly line by Henry Ford contributed to a spectacular increase of productivity. That success led in time to the idea that linearization, through its sequential and superposition biases, is the managerial solution to complex problems (Bratianu \& Vasilache, 2010). However, as Ohmae (1982, p. 13) remarks, "Phenomena and events in the real world do not fit a linear model. Hence, the most reliable means of dissecting a situation into its constituent parts and reassembling them into desired pattern is not a step-by-step methodology such as systems analysis. Rather, it is that ultimate nonlinear thinking".

Applying the superposition principle to the organizational knowledge by using a linear logic, someone may end up with the paradox of Albrecht Law (Albrecht, 2003, p. 4): "Intelligent people, when assembled into organization, will tend toward collective stupidity". That phenomenon is quite frequent in many situations as a result of the influence of organizational culture or managerial power in decision-making, or of organizational behavior based on group polarization (Alvesson \& Spicer, 2016). The superposition principle has been used also by Stewart (1997, p. XI) when he defined the intellectual capital: "Intellectual capital is the sum of everything everybody in a company knows that gives it a competitive edge. Unlike the assets with which business people and accountants are familiar - land, factories, equipment, cash - intellectual capital is intangible". Intellectual capital cannot be the sum of everybody's knowledge because knowledge does not respect the addition rule, as demonstrated by Bratianu (2009b).

Knowledge management deals with nonlinear intangible resources and any process of linearization and discretization creates the risk of getting large errors when we apply the linear logic in decision-making. For instance, when the recognition and motivational system for employees is based only on financial metrics, means to solve a nonlinear problem like emotional state of people by using a linear metric. Moreover, when these metrics are not based on the correlation between the work performance and the financial reward, people will not be satisfied with the final result. When intellectual capital is evaluated by using a set of linear items like in the case of the Austrian Law for intellectual capital reporting by the state universities, the final result may lead to many misinterpretations due to the errors produced in the linearization and discretization process. Research performed so far in the area of knowledge management and intellectual capital reveals the need of developing new metrics based on nonlinear thinking and complexity models.

\section{Conclusion}

Knowledge should be considered in its complexity as rational, emotional, and spiritual knowledge, and according to the entropic perspective we should understand the possibility of transforming one form of knowledge into another form. Knowledge is a nonlinear entity and knowledge management departs from this point of view from industrial management, which deals with linear entities. 
The purpose of this paper is to reveal the importance of understanding the processes of linearization and discretization used frequently in management and of being aware of the errors generated when they are applied to nonlinear entities like knowledge, intellectual capital and knowledge management. Linear thinking is so much used in our education and in solving everyday problems that many of us consider it as being the only way to approach in decision-making and solving problems. Linear thinking is based on the properties of linear spaces, which means that it operates with the addition and multiplication rules. However, knowledge and intellectual capital are nonlinear entities and they cannot be added or multiplied in a sense making approach. They result though integration and restructuring or even changing their initial nature.

Many shortcomings in understanding the nonlinearity of knowledge management come from the metaphors used by researchers in defining and explaining knowledge. For instance, in the first generations of knowledge metaphors researchers used in the source domains concepts like physical objects, stocks, flows, or stocks-and-flows. In all of these cases, the linear attributes from the source domain induced through the mapping function in the target domain the idea of linearity and discreteness. That generates in practice many errors in designing and using properly the metrics for evaluating and reporting intellectual capital of the companies. Linearization and discretization which are used currently in accounting have been extended in these reporting systems and produced many errors in interpreting the final values and in getting a correct correlation between the intangible resources of a company and its performance.

The conclusion is that linear metrics should be replaced by nonlinear ones and knowledge management should develop new principles in dealing with organizational knowledge and organizational intelligence.

\section{References}

Albrecht, K. (2003). The power of minds at work: Organizational intelligence in action. New York: American Management Association.

Alvesson, M., \& Spicer, A. (2016). The stupidity paradox: The power and pitfalls of functional stupidity at work. London: Profile Books.

Andriessen, D. (2004). Making sense of intellectual capital: designing a method for the validation of intangibles. Amsterdam: Elsevier.

Andriessen, D. (2006). On the metaphorical nature of intellectual capital: a textual analysis. Journal of Intellectual Capital, 7(1), 93-110.

Andriessen, D., \& Boom, M.d. (2007, May). Asian and Western intellectual capital in encounter. Paper presented at IC Congress 2007, Inholland University of Applied Sciences, Haarlem, The Netherlands.

Atwater, J.B., Kannan, V.R., \& Stephens, A.A. (2008). Cultivating systems thinking in the next generation of business leaders. Academy of Management Learning and Education, 7(1), 9-26.

Audi, R. (2011). Epistemology: A contemporary introduction to the theory of knowledge (3 ${ }^{\text {rd }}$ edition). New York: Routledge.

Barney, J.B., \& Clark, D.N. (2007). Resource-based theory: Creating and sustaining competitive advantage. Oxford: Oxford University Press. 
Baron, J. (2000). Thinking and deciding (3 ${ }^{\text {rd }}$ edition). Cambridge: Cambridge University Press.

Bratianu, C. (2009a). Challenges for knowledge management research. In Bratianu, C., Lixandroiu, D., \& Pop, A.N. (Eds.). Proceedings of the $4^{\text {th }}$ International Conference on Business Excellence, University "Transilvania" of Brasov, Brasov, Romania, 16-17 October 2009 (pp. 52-55). Brasov: Infotec.

Bratianu, C. (2009b). The frontier of linearity in the intellectual capital metaphor. In Stam, C. \& Andriessen, D. (Eds.). Proceedings of the European Conference on Intellectual Capital, Inholland University of Applied Sciences, Haarlem, The Netherlands, 28-29 April 2009 (pp. 97-103). Reading, UK: Academic Conferences and Publishing International.

Bratianu, C. (2014). Strategies to enhance intergenerational learning in universities. In Rooney, J., \& Murthy, V. (Eds.). Proceedings of the International Conference on Intellectual Capital, Knowledge Management and Organizational Learning, University of Sydney, Australia, 6-7 November 2014 (pp. 83-90). Reading: Academic Conferences and Publishing International.

Bratianu, C. (2018). Intellectual capital research and practice: 7 myths and one golden rule. Management \& Marketing. Challenges for the Knowledge Society, 13(2), 859-879.

Bratianu, C., \& Atluri, S.N. (1983). A hybrid finite element method for Stokes flow: Part I formulation and numerical studies. Computer Methods in Applied Mechanics and Engineering, 36(1), 23-37.

Bratianu, C., \& Bejinaru, R. (2017). Knowledge strategies for increasing IC of the universities. In Lopez, I.T., \& Serrasqueiro, R. (Eds.). Proceedings of the $9^{\text {th }}$ European Conference on Intellectual Capital, ECIC 2017 (pp.34-42). Instituto Universitario de Lisboa (ISCTEIUL), Lisbon, Portugal, 6-7 April 2017. Reading, UK: Academic Conferences and Publishing International.

Bratianu, C., \& Orzea, I. (2013). Emotional knowledge: The hidden part of the knowledge iceberg. In Janiunaite, B., Pundziene, A., \& Petraike, M. (Eds). Proceedings of the 14th European Conference on Knowledge Management, Kaunas University of Technology, Lithuania, 5-6 September 2013 (pp. 82-90). Reading: Academic Conferences and Publishing International.

Bratianu, C., \& Pinzaru, F. (2015). University governance as a strategic driving force. In Rouco, J.C.D. (Ed.). Proceedings of the $11^{\text {th }}$ European Conference on Management, Leadership and Governance (pp. 28-35). Military Academy, Lisbon, Portugal, 12-13 November 2015. Reading, UK: Academic Conferences and Publishing International.

Bratianu, C., \& Vasilache, S. (2010). A factorial analysis of the managerial linear thinking model. International Journal of Innovation and Learning, 8(4), 393-407.

Bryman, A. \& Bell, E. (2007). Business research methods. Second edition. Oxford, UK: Oxford University Press.

Damasio, A. (1999). The feelings of what happens: Body and emotions in the making of consciousness. New York: Harcourt.

Damasio, A. (2012). Self comes to mind: Constructing the conscious brain. New York: Vintage Books.

Dima, A.M., Hadad, S., \& Cantaragiu, R. (2016). A conceptual analysis of business-university knowledge transfer in the energy field. In Tantau, A., \& Hadad, S. (Eds.). Proceedings 
of the 10 th International Conference on Business Excellence (pp. 199-204). Bucharest University of Economic Studies, Bucharest, Romania, 3-4 March 2016. Bucharest: ASE Publishing House.

Dumay, J. (2009). Intellectual capital measurement: a critical approach. Journal of Intellectual Capital, 10(2), 190-210.

Edvinsson, L. (2002). Corporate longitude - navigating the knowledge economy. London:

PICBE $\mid 455$ Pearson.

Edvinsson, L. (2013). IC 21: reflections from 21 years of IC practice and theory. Journal of Intellectual Capital, 14(1), 163-172.

Gharajedaghi, J. (2006). Systems thinking. Managing chaos and complexity: A platform for designing business architecture ( $2^{\text {nd }}$ edition). Amsterdam: Elsevier.

Gladwell, M. (2005). Blink: The power of thinking without thinking. New York: Back Bay Books.

Grant, R.M. (1996). Toward a knowledge-based theory of the firm. Strategic Management Journal, 17 (Winter), 109-122.

Grant, R.M. (1997). The knowledge-based view of the firm: Implications for management practice. Long Range Planning, 30(3), 450-454.

Groves, K.S., Vance, C.M., \& Paik, Y. (2008). Linking linear/nonlinear thinking style balance and managerial ethical decision-making. Journal of Business Ethics, 80, 305-325.

Habersam, M., Piber, M., \& Skoog, M. (2018). Ten years of using knowledge balance sheets in Austrian public universities: a retrospective and prospective view. Journal of Intellectual Capital, 19(1), 34-52.

Habersam, M., Piber, M., \& Skoog, M. (2013). Knowledge balance sheets in Austrian universities: the implication, use, and re-shaping of measurement and management practices. Critical Perspectives on Accounting, 24(4/5), 319-337.

Hadad, S. (2017). Strategies for developing knowledge economy in Romania. Management \& Marketing. Challenges for the Knowledge Society, 12(3), 416-430.

Handy, C. (2002). The age of unreason: New thinking for a new world. London: Arrow Books.

Jashapara, A. (2011). Knowledge management: An integrated approach (2 $2^{\text {nd }}$ edition). London: Financial Times/ Prentice Hall.

Keeny, R.L. (1992). Value-focused thinking: A path to creative decision making. Cambridge, MA: Harvard University Press.

Kolb, A.Y., \& Kolb, D.A. (2005). Learning styles and learning spaces: Enhancing experiential learning in higher education. Academy of Management Learning \& Education, 4(2), 193-212.

Lakoff, G., \& Johnson, M. (1999). Philosophy in the flesh: the embodied mind and its challenge to the western thought. New York, NY: Basic Books.

Martin, R. (2007). The opposable mind: How successful leaders win through integrative thinking. Boston: Harvard Business School Press.

Maxwell, J.A. (2013). Qualitative research design. An interactive approach. Third Edition. Los Angelos, CA: SAGE.

Nonaka, I., \& Takeuchi, H. (1995). The knowledge -creating company: How Japanese companies create the dynamics of innovation. Oxford: Oxford University Press.

Ohmae, K. (1982). The mind of the strategist: The art of Japanese business. New York: McGraw-Hill. 
Powell, W.W., \& Snellman, K. (2004). The knowledge economy. Annual Review of Sociology, 30, 199-220.

Ricceri, F. (2008). Intellectual capital and knowledge management: strategic management of knowledge resources. London, UK: Routledge.

Roos, G., Pike, S., \& Fernström, L. (2005). Managing intellectual capital in practice. Amsterdam: Elsevier.

Senge, P. (1999). The fifth discipline: the art \& practice of the learning organization. New York, NY: Random House.

Sternberg, R.J. (1997). Thinking styles. Cambridge: Cambridge University Press.

Stewart, T. (1997). Intellectual capital: the new wealth of organization. New York, NY: Doubleday.

Sveiby, K.E. (1997). The new organizational wealth: managing and measuring knowledge based assets. San Francisco, CA: Berrett-Koehler.

Teece, D.J. (2009). Dynamic capabilities \& strategic management: organizing for innovation and growth. Oxford, UK: Oxford University Press.

Vance, C.M., Groves, K.S., Paik, Y., \& Kindler, H. (2007). Understanding and measuring linearnonlinear thinking style for enhanced management education and professional practice. Academy of Management Learning and Education, 6(2), 167-185.

Viedma, J.M. (2003). In search of intellectual capital general theory. Electronic Journal of Knowledge Management, 1(2), 213-226. 